
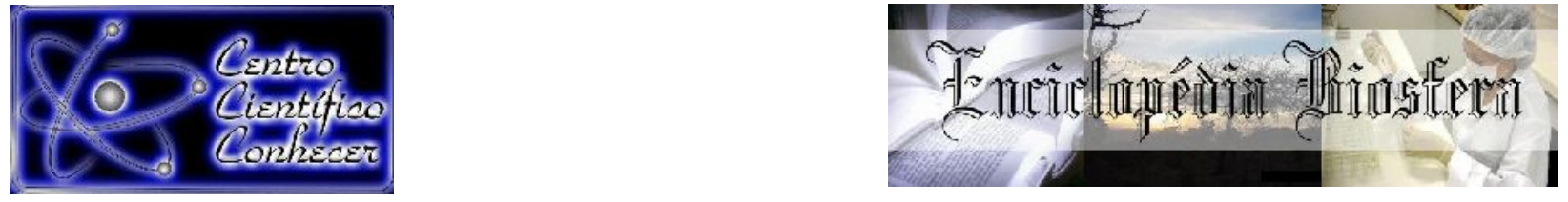

\title{
GESTÃO ORGANIZACIONAL NO SETOR PÚBLICO: ANALISANDO AÇÕES DE EXTENSÃO COM CARACTERÍSTICAS INTERDISCIPLINARES NA UFG
}

\author{
Lucas Fagundes Vaz'; Paulo Henrique Santana de Oliveira ${ }^{2}$, Fábio Ricardo Mizuno \\ Lemos $^{3}$, Laila Lidiane da Costa Galvão ${ }^{4}$ \\ ${ }^{1}$ Especialista em Gestão de Tecnologia da Informação pela Universidade Candido Mendes, \\ Rio de Janeiro-RJ, Brasil. (lucasfagundesvaz@gmail.com) \\ ${ }^{2}$ Mestre em Gestão Organizacional pelo Programa de Pós-Graduação em Gestão \\ Organizacional da Universidade Federal de Goiás, Catalão-GO, Brasil. \\ ${ }^{3}$ Doutor em Educação pela Universidade Federal de São Carlos, São Carlos-SP, Brasil. \\ ${ }^{4}$ Mestra em Gestão Organizacional pelo Programa de Pós-Graduação em Gestão \\ Organizacional da Universidade Federal de Goiás, Catalão-GO, Brasil.
}

Recebido em: 06/04/2018 - Aprovado em: 10/06/2018 - Publicado em: 20/06/2018 DOI: 10.18677/EnciBio_2018A133

\begin{abstract}
RESUMO
O presente trabalho buscou explorar os conceitos de extensão universitária e interdisciplinaridade no contexto da gestão organizacional, com intuito de investigar e compreender qual foi a efetividade da extensão universitária no período de 2007 a 2016 na Universidade Federal de Goiás (UFG) - Regional Goiás, tendo em vista a importância da extensão para as comunidades interna e externa a esta, assim como a relevância de ações interdisciplinares. O objetivo foi identificar as ações de extensão com características interdisciplinares e discuti-las. Após a extração das informações no sistema disponível no site da Pró-Reitoria de Extensão e Cultura PROEC/UFG, foram analisadas as ações dentro do período informado, no âmbito da interdisciplinaridade. A metodologia utilizada foi documental, de cunho exploratório e descritivo. Conforme informações levantadas no sistema da PROEC e nos relatórios de gestão, foi possível classificar as ações de extensão, bem como relacionar tais ações ao crescimento do quantitativo de servidores da Regional Goiás. As ações de extensão totalizaram: quatro em 2013, sendo três interdisciplinares; 17 em 2014, sendo 10 interdisciplinares; 55 em 2015, sendo 23 interdisciplinares e 67 em 2016, sendo 25 interdisciplinares. Apesar do avanço em contexto geral das ações de extensão e das ações com características interdisciplinares, é importante buscar a ampliação da interdisciplinaridade, pelo seu potencial de favorecimento da construção coletiva e do compartilhamento de saberes/conhecimentos, entre diversas disciplinas de vários cursos existentes na regional Goiás.
\end{abstract}

PALAVRAS-CHAVE: ações de extensão; interdisciplinaridade; sistema de gerenciamento.

\section{ORGANIZATIONAL MANAGEMENT IN THE PUBLIC SECTOR: ANALYZING EXTENSION ACTIONS WITH INTERDISCIPLINARY CHARACTERISTICS IN THE UFG}

\section{ABSTRACT}

The present work explored the concepts of university extension and interdisciplinarity in the context of organizational management, aiming at investigating and 
understanding the effectiveness of university extension in the period from 2007 to 2016 at the Universidade Federal de Goiás (UFG) - Regional Goiás, considering the importance of the extension to the internal and external communities to this, as well as the relevance of interdisciplinary actions. The objective was to identify extension actions with interdisciplinary characteristics and to discuss them. After extracting the information in the system available on the website of the Pró-Reitoria de Extensão e Cultura - PROEC/UFG, were analyzed the actions within the period informed, within the scope of interdisciplinarity. The methodology used was documentary, exploratory and descriptive. According to information collected in the PROEC system and in the management reports, it was possible to classify the extension actions, as well as to relate such actions to the growth of the number of servers of the Regional Goiás. The extension actions totaled: 4 in 2013, being 3 interdisciplinary; 17 in 2014, of which 10 are interdisciplinary; 55 in 2015, being 23 interdisciplinary and 67 in 2016, being 25 interdisciplinary. Although the advance in the general context of extension actions and actions with interdisciplinary characteristics, it is important to seek the extension of interdisciplinarity, for its potential of favoring the collective construction and sharing of knowledge, between several disciplines of several existing courses in the Regional Goiás.

KEYWORDS: extension actions; interdisciplinarity; management system.

\section{INTRODUÇÃO}

Extensão universitária é um dos componentes que constitui a estrutura tríplice (ensino, pesquisa e extensão) que as Universidades Públicas e Institutos Federais brasileiros têm adotado como modelo. Este paradigma é aplicado desde a segunda metade da década de 1960, segundo Hunger et al. (2014), momento em que ocorreu a reforma universitária através da lei $n .05 .540 / 68$, e a partir deste marco as instituições de ensino superior públicas inseriram a extensão universitária em seus estatutos, de forma que fosse indissociável do ensino e da pesquisa.

A extensão universitária tem potencial para colaborar com o desenvolvimento da cidadania, bem como, para a transformação efetiva da sociedade, pensamento este que vai ao encontro do entendimento de Costa (2014), quando afirma que as lições e experiências resultantes das ações de extensão podem beneficiar toda uma comunidade. Através das ações de extensão consegue-se, portanto, ir além dos limites espaciais/geográficos das instituições e chegar à comunidade, auxiliando-a em demandas sociais, culturais, artísticas, desportivas, científicas ou tecnológicas. Gomes et al. (2014) ressaltam os benefícios que a extensão universitária proporciona aos discentes envolvidos na ação:

[...] são retiradas lições, experiências, exemplos que enaltecem o processo de formação acadêmica. [...] novos cenários de aprendizagem, aproximando-os do contexto social, político e econômico nos quais têm a oportunidade de apreender a dinâmica das relações de poder que permeiam este contexto, o que lhes proporcionam um conhecimento que se encontra para além dos "muros acadêmicos" (p. 69).

Mas para que ocorram tais transformações, as ações extensionistas, de acordo com Braga et al. (2015), necessitam mobilizar os estudantes acadêmicos a participarem de práticas de extensão voltadas para um movimento universitário democrático e socialmente engajado com a comunidade do entorno das instituições. 
Ribeiro (2009), contudo, ressalta que a extensão universitária também pode ser visualizada do ponto de vista assistencialista, quando o extensionista usa a sociedade como recipiente de depósito de conhecimentos ignorando seus valores, crenças e saberes, associando a ideia de transmissão, doação, messianismo, invasão cultural. Nesse contexto, segundo Mota (2013), a gestão universitária que tem a preocupação com a excelência, deve encarar o desafio de estimular um de seus principais protagonistas, o estudante, a desenvolver não só os conhecimentos ligados aos componentes curriculares, mas também habilidades e atitudes cidadãs.

Lacerda et al. (2016) ressaltam de forma clara que o acesso aos conhecimentos e saberes provenientes de pesquisas nas universidades devem ser colocados à disposição do público externo para que haja transformação social tendo como ponto de partida o acesso a esta informação.

A extensão é análoga a uma "via de mão dupla", onde há uma troca de experiências e saberes entre o(s) extensionista(s) e a comunidade, ou seja, a troca de saberes, conhecimentos e experiência se faz de forma mútua entre as partes (LACERDA et al., 2016).

A atitude estudantil diante da extensão universitária é uma das capacidades e potencialidades a serem exploradas, pois permitirá que os extensionistas construam aprendizados que aglutinam vários conteúdos, de diversas áreas do conhecimento e que podem estar interligados, e a partir disso propiciar novas experiências no meio acadêmico, associadas principalmente ao contexto histórico, à realidade vivida pelos estudantes (SADOYAMA, 2015).

Para Finger et al. (2017) a educação precisa ser pensada e operacionalizada de modo interdisciplinar, de forma que o processo de ensino-aprendizagem deixe de ser executado da maneira convencional - professor transmissor e aluno receptor - e passe a oportunizar ao aluno um papel de sujeito ativo neste processo. É preciso considerar ensinar o aluno a pensar, planejar e encontrar soluções para lidar com situações-problema tanto no ambiente acadêmico quanto na vida profissional, e não se consegue isto fazendo sempre da mesma forma - ensino convencional. Portanto, os autores ressaltam que ao executar atividades integradoras e ao mesmo tempo com característica interdisciplinar, ocorrem melhorias em relação ao aprendizado dos alunos.

Fortunato et al. (2013) afirmam que o ensino deve ser pensado de forma harmoniosa entre todos os atores envolvidos - alunos, professores e gestores, de forma que cada um dê sua parcela de contribuição, entretanto, esclarecem que não é bem o que acontece no cotidiano das instituições de ensino, o que leva o estudante a considerar que:

[...] o currículo está dividido em pequenas caixas de conteúdos, fechados em si e sem conexão com outros campos do conhecimento, ainda que afins. Nesta fragmentação de vivências e experiências acadêmicas e sociais, ocorre uma regressão à capacidade de compreender o contexto macro, no qual o conhecimento torna-se mais amplo e significativo (FORTUNATO et al., 2013, p. 9).

Considerando todo o exposto, ou seja, a importância das ações de extensão, pautadas principalmente na integração de saberes, e o potencial que têm de transformação tanto do meio acadêmico, quanto da comunidade externa, o objetivo deste estudo foi identificar e discutir as ações de extensão com características 
interdisciplinares da Universidade Federal de Goiás (UFG), Regional Goiás, no período de 2007 a 2016.

\section{MATERIAL E MÉTODOS}

A metodologia utilizada foi documental, de cunho exploratório e descritivo. Foram consultados dados públicos relativos às ações de extensão realizadas na UFG Regional Goiás no período de 2007 a 2016, coletados através de sistema web disponibilizado no site da Pró-Reitoria de Extensão e Cultura (PROEC) ${ }^{1}$. Posteriormente, as informações relevantes para a pesquisa foram organizadas em planilhas eletrônicas.

\section{RESULTADOS E DISCUSSÃO}

Para análise das ações de extensão, fez-se necessário entender a evolução histórica da instituição. A primeira Faculdade de Direito do estado foi criada em Goiás - GO, que anos mais tarde, após convênio firmado entre a prefeitura desta cidade e a Universidade Federal de Goiás, em 1990, passou a ser denominada: Extensão da Faculdade de Direito. Seguindo a trajetória, em 2009 com expansões e novos cursos já agregados, a Faculdade de Extensão de Direito passou a ser denominada: Campus Cidade de Goiás e posteriormente em 2015 devido a alterações no estatuto interno da UFG, passou a ser denominada Regional Goiás (CARVALHO 2015).

A Regional Goiás oferece sete cursos superiores, sendo estes: Administração (bacharelado), Arquitetura e Urbanismo, Direito (bacharelado), Educação do Campo (licenciatura), Filosofia (licenciatura), Filosofia (bacharelado) e Serviço Social (bacharelado) (CARVALHO 2016).

Através de levantamento documental, foi possível analisar relatórios de gestão compreendendo o período entre 2013 e 2017, em que se pôde visualizar o quantitativo de servidores para cada ano no período selecionado, números estes, que influenciam diretamente na expansão da universidade e que serão adiante relacionados com as ações de extensão.

TABELA 1. Servidores docentes da UFG Regional Goiás contemplando o período entre 2013 e 2017 (até os dias atuais)

\begin{tabular}{cccccc}
\hline Servidores & Ano & Federais & Municipais & Terceirizados & Total \\
\hline \multirow{3}{*}{ Docentes } & 2017 & 90 & 1 & 0 & 91 \\
& 2016 & 90 & 1 & 0 & 91 \\
& 2014 & 71 & 3 & 0 & 74 \\
& 66 & 3 & 0 & 69 \\
\hline
\end{tabular}

\footnotetext{
${ }^{1}$ http://sistemas.ufg.br/SIEC/catalogo proec/catalogo.php
} 
TABELA 2. Servidores técnicos administrativos da UFG Regional Goiás contemplando o período entre 2013 e 2017 (até os dias atuais)

\begin{tabular}{cccccc}
\hline Servidores & Ano & Federais & Municipais & Terceirizados & Total \\
\hline & 2017 & 28 & 2 & 23 & 53 \\
& 2016 & 28 & 2 & 23 & 53 \\
Técnicos & 2015 & 28 & 3 & 23 & 54 \\
Administrativos & 2014 & 28 & 2 & 19 & 49 \\
& 2013 & 17 & 4 & 7 & 28 \\
\hline
\end{tabular}

Fonte: elaborado pelos autores.

Conforme exposto na metodologia, os dados disponibilizados no sistema online da PROEC contemplavam informações sobre extensão universitária entre o período de 2007 e 2016. Estes foram exportados para planilhas eletrônicas de forma a permitir uma análise estatística rigorosa a fim de responder às questões levantadas.

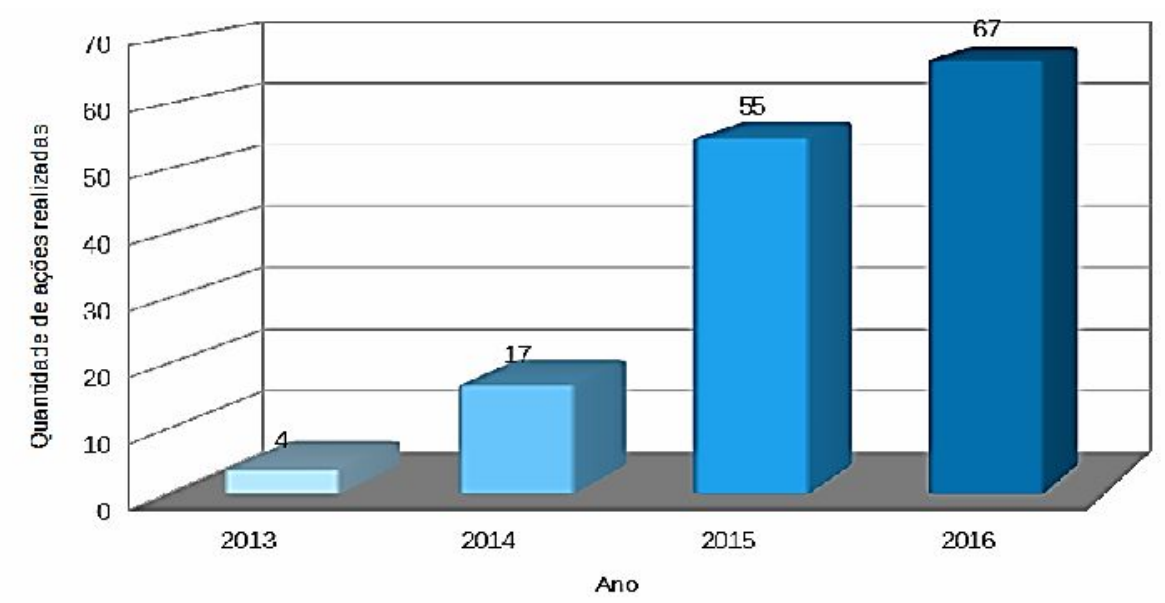

FIGURA 1. Total de ações de extensão realizadas por ano (elaborado pelos autores).

$\mathrm{Na}$ figura 1 é exibido o total de todas as ações de extensão realizadas, salvo o período de 2007 a 2012 que o sistema da PROEEC retornou a informação de que não existiam ações cadastradas. Este fato pode estar relacionado ao período de estruturação que a Instituição vivenciou. Conforme dados das tabelas 1 e 2, houve aumento de profissionais técnicos administrativos e docentes no período entre 2013 e 2016. Não foram encontrados relatórios com quantitativo de servidores para o interstício de 2007 a 2012. Desse modo, foi possível relacionar os dados do relatório de gestão com os encontrados no sistema da PROEC. Na figura 2 é mostrada a classificação e o número de ações interdisciplinares e não interdisciplinares realizadas na regional. 


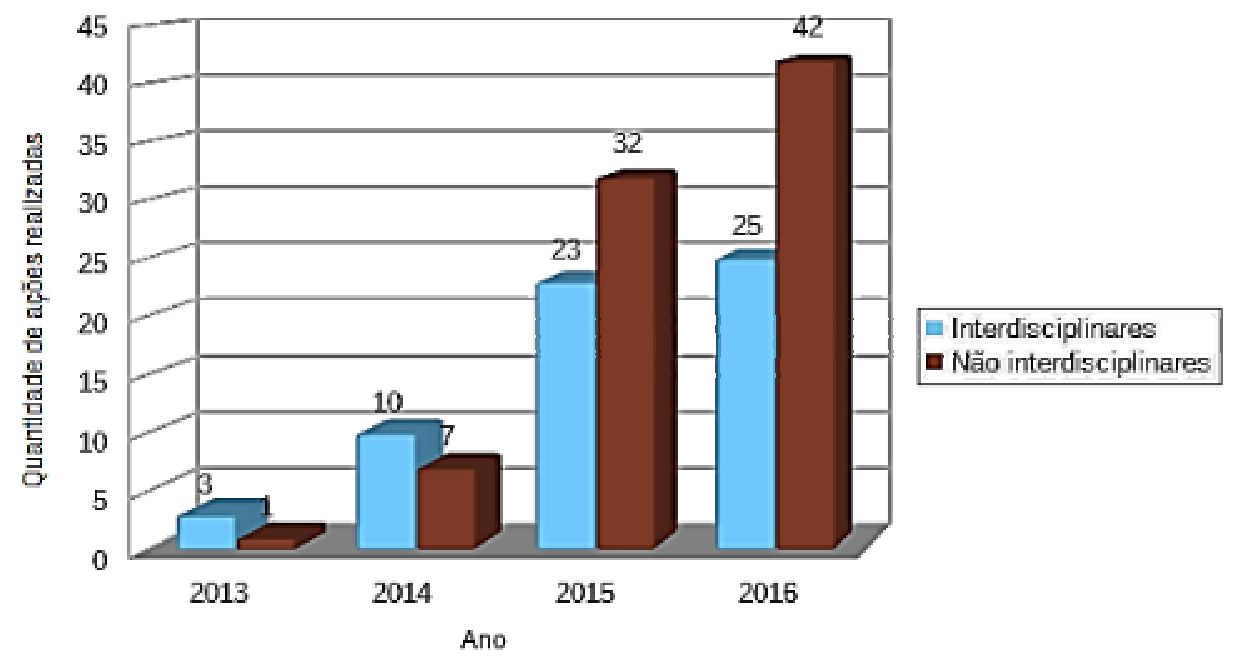

FIGURA 2. Total de ações interdisciplinares e não interdisciplinares (elaborado pelos autores).

O número de ações interdisciplinares foi bem próximo ao número de ações não interdisciplinares quando avaliado o somatório total dos anos contemplados deste estudo, sendo os valores: 61 ações interdisciplinares e 82 não interdisciplinares. Essa proximidade permitiu avaliar que a Regional Goiás possui visão da importância e das transformações que podem ser obtidas vindas da aplicação e desenvolvimento de ações interdisciplinares. Nunes et al. (2017) detalha sobre interdisciplinaridade no âmbito da formação universitária ao colocar:

\begin{abstract}
A instituição de práticas interdisciplinares e intersetoriais no âmbito da formação universitária implica admitir que é impossível processála com base em uma única disciplina de conhecimento ou área profissional. Isso se deve à complexidade dos fenômenos e problemáticas sociais, exigindo articulação de saberes e práticas ao considerar a dinâmica das relações que se definem e redefinem na realidade social (p. 3).
\end{abstract}

Os autores acima expressam similar elucidação às colocações levantadas na introdução do presente trabalho, especialmente o que foi colocado por Lacerda et al. (2016), Gomes et al. (2014) e Braga et al. (2015). É válido frisar que a Regional Goiás é uma instituição relativamente nova. No tocante ao período de funcionamento, considera-se que qualquer organização/instituição leva algum tempo para institucionalizar suas regras e normas. Além disso, as instituições de ensino são organizações educacionais cuja ecologia de saberes e conhecimentos é muito rica, a julgar pela formação acadêmica e titulação de seus membros - professores, técnicos administrativos e até mesmo alunos.

Ressalta-se ainda, que conforme regimento desta universidade, todos os servidores sejam eles técnicos administrativos ou docentes têm consciência da importância da realização de ações de extensão. Entretanto, há fatores que fazem com que a produção seja maior na categoria docente, pois conforme regras regimentais, docentes obrigatoriamente devem atingir uma pontuação mínima para que progridam em suas respectivas carreiras. A título de exemplo, uma das etapas que o docente deve pontuar em ações de extensão é no período de estágio 
probatório conforme redação do art. 15 da Resolução - CONSUNI nำ 18/2017 (BRASIL, 2017) da UFG:

A CAD pontuará as atividades de ensino, produção intelectual, pesquisa, extensão, administração, qualificação e outras atividades do professor em estágio probatório, no período de avaliação de desempenho, a cada ano, registrando a pontuação.

Segundo as regras existentes no regimento da universidade, técnicos administrativos podem coordenar e participar de ações de extensão, porém, os mesmos não têm obrigatoriedade de executar ações de extensão universitária, bem como ensino e pesquisa. Salienta-se, ainda que tanto os servidores técnicos administrativos quanto os docentes da regional em questão, entendem 0 real propósito da universidade pública, de não existir apenas para o processo formativo de alunos, mas também para cumprir com seu dever institucional e levar seus processos, produtos e serviços para o ambiente externo.

É importante pontuar que todos os projetos de extensão têm relevância e contribuem de forma positiva para que as instituições de ensino se mantenham saudáveis e, além disso, seja agente transformador da sociedade no sentido de levar o conhecimento para além dos muros das instituições e para que aconteça a troca de conhecimentos e saberes. Para consolidar esta afirmação, serve de exemplo fidedigno o trabalho desenvolvido por Lacerda et al. (2016), que se fizeram como parceiros, na forma de projeto de extensão, no célebre e amplamente conhecido Projeto Rondon. Certamente este projeto expandiu horizontes e provou que as universidades precisam romper paradigmas e cada vez mais fazerem proposições extensionistas.

Ressalta-se, ainda, que conforme resultados encontrados faz-se necessário que os alunos, servidores técnicos administrativos e docentes entendam de forma mais aprofundada a função extremamente relevante que a extensão universitária desempenha tanto para a instituição de ensino quanto para as pessoas que nela atuam - alunos, professores e técnicos.

Outro ponto que merece destaque é a dificuldade apontada por Fortunato et al. (2013) quando elucidam que há falta de comunicação entre os protagonistas das instituições de ensino no sentido de executar de fato a modalidade ensino interdisciplinar, seja em sala de aula (ensino), pesquisa ou na extensão universitária. Neste sentido, pode-se entender que as ações de extensão universitária com características interdisciplinares é algo que se faz com extrema complexidade a partir de fatores negativos que por ventura são impeditivos potenciais.

\section{CONCLUSÃO}

Frente ao estudo, foi possível notar o avanço que a regional em questão teve no decorrer dos anos de sua existência. As ações de extensão mantiveram sempre crescimento satisfatório, como se verificou nos dados apresentados nas figuras $1 \mathrm{e}$ 2, cumprindo o proposto pelas resoluções da universidade, proporcionando conhecimento, informações, aprendizagem e interação para/com a comunidade interna e externa. Pode-se esperar ainda, com o histórico da proporção entre quantitativo de servidores e número de ações de extensão, que a instituição desenvolva nos próximos anos maior número de projetos.

Em relação às ações interdisciplinares, se nos anos de 2013 e 2014 eram a maioria, o mesmo não ocorreu nos anos seguintes, apesar do considerável 
aumento. A importância de ampliar as ações interdisciplinares está no potencial que têm de integrar diversas disciplinas de vários cursos existentes na regional, trazendo benefícios relacionados, principalmente, à construção coletiva e ao compartilhamento de saberes/conhecimentos.

Recomenda-se para trabalhos futuros o aprofundamento deste tema, levando em consideração as características interdisciplinares, a fim de investigar se as ações de extensão continuam avançando e de que maneira isso está ocorrendo.

\section{REFERÊNCIAS}

BRAGA, A. W. V.; ABREY, L. D. P.; SOUZA, L. A.; IBIAPINA, M. L.; SILVA, R. M. G. Extensão universitária e educação: contribuições do projeto PREVEST/UVA à formação acadêmica e social. SANARE: Revista de Políticas Públicas, v. 14, n. 1, p. 93-103, jan./jun. $2015 . \quad$ Disponível em: <https://sanare.emnuvens.com.br/sanare/article/view/616>.

BRASIL. Universidade Federal de Goiás. Resolução - CONSUNI no 18/2017. Dispõe sobre normas para avaliação em relação a estágio probatório, progressão funcional, promoção, aceleração da promoção, retribuição por titulação e alteração de denominação do Professor da Carreira do Magistério Superior e estágio probatório do Professor Titular Livre do Magistério Superior e revoga as disposições em contrário. Goiânia, GO, 2017. Disponível em: < https://sistemas.ufg.br/consultas_publicas/resolucoes/arquivos/Resolucao_CONSUN I_2017_0018.pdf>.

CARVALHO, M. M. de. Relatório simplificado de gestão. Cidade de Goiás: Universidade Federal de Goiás Regional Goiás, 2015.

CARVALHO, M. M. de. Relatório simplificado de gestão. Cidade de Goiás: Universidade Federal de Goiás Regional Goiás, 2016.

COSTA R. P. A extensão universitária e o ambiente educacional popular. Revista do Centro Universitário Moura Lacerda, v. 16, n. 16, p. 133-144, 2014. Disponível em: $\quad$ <http://portalmouralacerda.com.br/wp-content/uploads/2016/06/E_Novapasta_Montagem-16-2014-2.compressed.pdf\#page=133>.

FINGER, D; SOUZA, J. B.; POTRICH, T. Descortinando enfermagem através da arte: uma experiência integradora em busca da interdisciplinaridade. Florianópolis: Revista Eletrônica de Extensão, v. 14, n. 25, p. 173-181, 2017. Disponível em: <http://dx.doi.org/10.5007/1807-0221.2017v14n25p173>. Doi: 10.5007/18070221.2017v14n25p173.

FORTUNATO, R.; CONFORTIN, R.; SILVA, R. T. da. Interdisciplinaridade nas escolas de educação básica: da retórica à efetiva ação pedagógica. Revista de Educação do Ideau, v. 8, n. 17, p. 1-14, 2013. Disponível em: $<$ https://www.ideau.com.br/getulio/restrito/upload/revistasartigos/28_1.pdf>.

GOMES, N. P.; SANTOS, A. B.; ABIB, S. W.; SANTOS, V. M.; FARIAS, Z. I.; CARNEIRO, J. B. Extensão Universitária: política educacional que orienta políticas públicas locais. Cidadania em Ação: Revista de Extensão e Cultura, v. 8, n. 2, p. 
65-79,

2014.

Disponível

em:

<http://www.revistas.udesc.br/index.php/cidadaniaemacao/article/view/4384/pdf_130

$>$.

HUNGER D.; ROSSI F.; PEREIRA J. M.; NOZAKI J. M. O dilema extensão universitária. Educação em Revista, v. 30, n.03, p. 335-354, 2014. Disponível em: <http://dx.doi.org/10.1590/S0102-46982014005000004>. Doi: 10.1590/S010246982014005000004.

LACERDA, S.; GOMES, B.; BORGES, P.; CORREA, T.; MARTINELLI, B.; GASPAR, B. O Projeto Rondon no município de Denise-MT. Revista Eletrônica de Extensão, v. 13, n. 21 , p. 116-131, 2016. Disponível em: <http://dx.doi.org/10.5007/18070221.2016v12n21p116>. Doi: 10.5007/1807-0221.2016v12n21p116.

MOTA, R. Prefácio. In: COLOMBO, S. S. Gestão universitária: os caminhos para a excelência. Porto Alegre: Penso, 2013. p. 11-14.

NUNES M. A.; COMERLATTO D.; KLEBA M. E. Práticas interdisciplinares e intersetoriais na formação profissional: uma pauta para a extensão universitária. Seminário Internacional sobre Desenvolvimento Regional, v. 8, p. 1-18, 2017. Disponível em: <http://online.unisc.br/acadnet/anais/index.php/sidr/article/view/16779/4332>.

RIBEIRO, K. S. Q. S. A experiência na extensão popular e a formação acadêmica em fisioterapia. Cadernos Cedes, v. 29, n. 79, p. 335-346, set./dez. 2009. Disponível em: <http://dx.doi.org/10.1590/S0101-32622009000300004>. Doi: 10.1590/S0101-32622009000300004.

SADOYAMA, A. S. P. Ciência com consciência: o desafio de ser o andarilho de fronteiras epistemológicas. In: COSTA, António P.; CASTRO, Paulo A. Ensino Interdisciplinar: um mundo, diferentes olhares e muitos caminhos. Oliveira de Azeméis, Portugal: Ludomedia, 2015. p. 39-56. 